\title{
Estudo Clínico Aleatorizado com Grupo Controle e Mascaramento Duplo da Maturação do Colo Uterino pela Hialuronidase em Gestações a Termo.
}

Autor: Maria Delizete Bentivegna Spallicci

Orientador: Prof. Dr. Roberto Eduardo Bittar

Tese de doutorado apresentada à Faculdade de Medicina da Universidade de São Paulo, Departamento de Obstetrícia, em 17 de dezembro de 2002.

Estudo clínico aleatorizado com grupo controle e mascaramento duplo da maturação do colo uterino pela hialuronidase em gestações a termo.

Objetivo: Investigar a ação da injeção intracervical da hialuronidase na maturação do colo uterino em gestações a termo, com indice Bishop simplificado menor que 5, sem necessidade de hospitalização.

Casuística e Métodos: a 168 gestantes do HU-USP foram administradas $20000 \mathrm{U}$ de hialuronidase liofilizada (5 ml) ou placebo em dois pontos do colo uterino. A substância (ativa ou placebo) era administrada. Se após $48 \mathrm{~h} \mathrm{o}$ Bishops < 5, uma segunda dose era administrada.

Resultados: Para alcançar Bishop > 5 foi necessária uma única dose para $55 \%$ das 83 pacientes que receberam hialuronidase (das 85 que receberam placebo $=7 \%$ ). No caso da administração da segunda dose, os resultados foram positivos em 93\% das gestantes do grupo da hialuronidase (placebo $=21 \%$ ). O tempo médio de trabalho de parto no grupo de nuliparas que receberam hialuronidase foi de $7 \mathrm{~h}$ e de $5 \mathrm{~h}$ nas multiparas (placebo= $13 \mathrm{~h} \mathrm{e} 10 \mathrm{~h}$ ). O tempo médio de indução no grupo de nuliparas que receberam hialuronidase foi $12 \mathrm{~h}$ e $7 \mathrm{~h}$ nas multiparas (placebo=36 h e 21 h). Não houve hipercontratilidade ou hipertonia uterina. A incidência de parto vaginal nas gestantes da hialuronidase foi $83 \%$ (placebo- $=51 \%$ ). Para gestantes com histórico de cesárea anterior a incidência de parto vaginal no grupo hialuronidase foi $69 \%$ (placebo= 13\%).

Conclusão: A injeção intracervical de hialuronidase é método simples, efetivo e sem risco, mesmo para as gestantes com cesárea anterior, e que favorece a maturação cervical com o objetivo de reduzir a duração do trabalho de parto, bem como de viabilizar o parto por via vaginal, sem efeitos adversos para a gestante e para o feto.

Palavras-chave: Trabalho de parto. Parto normal. Cesárea. Índice de Bishop.

\section{Sistema de Defesa Antioxidante Hepático de Ratas Prenhes Diabéticas Tratadas com Extrato de Ginkgo biloba: Repercussão sobre a Performance Reprodutiva e o Resultado Perinatal}

\author{
Autora: Fernanda Cristina Guassú Almeida \\ Orientadora: Marilza Vieira Cunha Rudge \\ Co-orientadora: Ione Pellegatti Lemonica
}

Tese de doutorado apresentada ao Departamento de Ginecologia e Obstetrícia da Faculdade de Medicina de Botucatu - UNESP em 25/07/2002

O objetivo do presente trabalho foi estudar a influência do diabete e do tratamento com extrato de G.biloba (EGb 761) sobre o sistema de defesa antioxidante hepático (catalase, superóxido dismutase, glutationa peroxidase e glutationa total) de ratas e de seus recém-nascidos correlacionando com os resultados de performance reprodutiva e perinatal. Ratas Wistar prenhes foram divididas em seis grupos experimentais, de acordo com a presença ou não de diabete e em função do tratamento ou não com EGb 761 ou com o seu veículo. O diabete foi induzido sete dias antes do acasalamento pela injeção intravenosa de streptozotocin (40 mg/kg). O tratamento foi realizado por gavage na dose de $200 \mathrm{mg} / \mathrm{kg} /$ dia durante todo o período de prenhez. No $21^{\circ}$ dia da prenhez, as ratas foram mortas para determinação dos parâmetros relacionados ao sistema de defesa antioxidante hepático, à performance reprodutiva e ao resultado perinatal. O diabete mater- no grave, caracterizado por hiperglicemia maior que 200 $\mathrm{mg} / \mathrm{dl}$ e diminuição da atividade hepática da glutationa peroxidase e dos níveis hepáticos de glutationa total, associou-se à redução do número de corpos lúteos, de implantações, de fetos vivos, aumento do número de reabsorções embrionárias e da porcentagem de perda pós-implantação, maior incidência de recém-nascidos apresentando restrição de crescimento, malformações e diminuição da atividade hepática da catalase e dos niveis hepáticos de glutationa total. O tratamento de ratas diabéticas prenhes com EGb 761 na dose de 200 $\mathrm{mg} / \mathrm{kg} /$ dia não alterou os parâmetros antioxidantes materno e fetal analisados, não melhorando a performance reprodutiva e o resultado perinatal. Apoio financeiro: FAPESP e CAPES

Palavras-chave: Diabete melito. Malformações fetais. Estudo experimental. 